\title{
Features of the Academic and Pedagogical Communication in Virtual Environment
}

\author{
Ivanka T. Mavrodieva, Todor S. Simeonov, Anita P. Nikolova \\ Sofia University St. "Kliment Ohridski”, Sofia, Bulgaria
}

\begin{abstract}
There is an unbreakable bond between communication and knowledge. The philosophical realm that dwells on the nature of knowledge, known as epistemology, is mostly concerned with the discussion of how we acquire knowledge. Our main task in this article is to survey the contribution of different scientists, schools, research teams, scientific journals, and e-resources in establishing the fields of the academic and pedagogical communication. Our second task is to contrast the features of the two fields in terms of channels, practices, and genres. By academic communication, we define a term that encompasses the discourses conducted between the scientific community members and the lecturer-students interactions, where by pedagogical communication in this article we will refer to the educational interactions between the teachers and students at schools. We are going to delve into exploring the features of academic and pedagogical communication in traditional oral and written academic communication, as well as in virtual environment.
\end{abstract}

Keywords: academic communication, pedagogical communication, virtual environment, virtual pedagogical rhetoric

\section{Introduction}

During the last two decades, communication in universities and schools has been changed. The changes are dynamic and some of the factors are the rapid development of the Internet, social networks, platforms, e-resources, software programs, etc. The article is an attempt to identify some of the changes in academic communication at the universities and in pedagogical communication at the schools and the focus is on the communication channels and genres. At the same time, the article aims to present general and specific features of academic and pedagogical communication as present phenomena. The description and comparative approach have been used to present the features from theoretical and methodological standpoints. Simultaneously, the text does not claim completeness. The article presents results from the activities under project "Developing Competences and Improving Skills for New Research Methods and Methodologies by Junior Researchers".

\section{Theoretical and Methodological Perspectives on Academic Communication}

A close look at the list of theoretical publications on academic communication displays that they are not

Ivanka Todorova Mavrodieva-Georgieva, professor, Doc. Hab./DSc and Ph.D., Faculty of Philosophy, Sofia University St. "Kliment Ohridski", Sofia, Bulgaria.

Todor Simeonov Simeonov, Ph.D., Department of Rhetoric, Sofia University St. "Kliment Ohridski", Sofia, Bulgaria.

Anita Petrova Nikolova, Ph.D. student, Department of Rhetoric, Sofia University St. "Kliment Ohridski”, Sofia, Bulgaria.

${ }^{1}$ Contract №DM10/2 from 14th December 2016 under National Science Fund of Bulgaria, with Sofia University "St. Kliment Ohridski" being the base organization. 
numerous. We have selected the information from books and articles about rhetoric, academic communication, academic writing, pedagogical rhetoric, etc.

The connections between the academic writing and academic discourse are found in the articles by Ken Hyland who has done research concerned with these topics. He is interested in the persuasion in academic metadiscourse (Hyland, 1997). Hyland expanded the research field and opened new sub-fields for, e.g., the options of identity in academic writing (Hyland, 2002b) and citation, as well as reference (Hyland, 2003). He introduced the topic about self-citation and self-reference and he discussed the credibility and promotion in academic publication (Hyland, 2003). Begona Carrascal also discussed the role of citations, quotations, and authority in the scholarly papers (Carrascal \& Hundleby, 2011, p. 9).

As we mentioned above, the metadiscourse is investigated by different scientists from various standpoints. Ken Hyland is interested in persuasion and context and in the role of pragmatics in the academic metadiscourse (Hyland, 1997). He discussed the topic of authority and authorial identity in academic writing and investigated the notions "academic literacy" and "authorial identity" on the linguistic level (Hyland, 2002a, pp. 1091-1111). Hyland concluded that "...rhetorical identity is influenced by the writer's background and this becomes more intricate for students familiar with intellectual traditions which may be very different from those practiced in English context" (Hyland, 2002a, pp. 1110-1111).

Begona Carrascal and Hundleby focused on the authority argument in academic communication and explained that

Testimony is always based on same appeals to the "authority" of the sources, and hearer to accept what is so, we could always consider its use as argumentative, because by saying so, we give a reason to hearer to accept what is aid. But this word takes us too far, and we would have to consider almost all discourse uses as argumentative. (Carrascal \& Hundleby, 2011, p. 9)

Carrascal concluded "We can gather those possibilities in two general positions":

(1) We really have no specific thoughts about the matter, but we think that the authority quoted is competent enough and that we are in no position to have a better thought about it. In consequence, we accept (tentatively) the quote (and the appeal to the authority that goes with it) without any further questions, knowing that it has already been contrasted in a previous paper. Instead of looking for a possible alternative view or explanation, we only adopt it;

(2) The claim proposed by the authority is coherent with the beliefs we already have, and, in adopting it, we reinforce our prior beliefs (Carrascal \& Hundleby, 2011, p. 10). A conclusion could be drawn that academic identity cannot be divided categorically and that authorship, citations, and quotations increase the persuasive effect and they support the building or personal recognition, authority, and place in academic communities.

We are in agreement with Carrascal's and Hyland's views and we can add to these that Ivanka Mavrodieva and the co-author Yovka Tisheva have focused on academic communication and academic writing in the books "Academic Communication" (2010), "Academic Writing for PhD Students and Postdoc" (2014), and "Academic Writing for Students" (2016). Mavrodieva analysed academic presentations (2012) and virtual academic communication (2011). It is very important to say that verbal and visual argumentation in the academic presentations and the scientific texts are an inseparable part of the academic communication. Simultaneously, the academic communication enlarges its field of manifestation and nowadays more university lecturers create and maintain personal websites or academic blogs, as well as they use social networks 
(Facebook, LinkedIn, Instagram, Twitter, etc.) to organise the education process and share scientific knowledge. The academic communication is not only closed in the auditoriums and rooms of the universities, it is realized in the virtual environment using software and programs, for example, Moodle. Students and professors can watch video lectures organized as and presented as massive open online courses (MOOCs). The most notable websites providing MOOCs are Coursera, Edx, Ivesity, etc. In these cases, the virtual academic communication includes the principles to share the knowledge and to guarantee open access to the scientific information, as well as to present the lectures of leading lecturers from different universities.

From methodological standpoint, the contemporary status of the socio-cultural prestige of science, academic writing, language, metadiscourse, rhetoric, etc., is an important subject which requires profound and interdisciplinary research. Our brief survey of theory shows that academic communication is not studied sufficiently and it provokes our research interest in that matter based on the need to give answers of some questions. At the same time, we understand that it is not possible to explain plenty of the complex topics and we would like to emphasize on the further necessity to investigate this cross-point area.

\section{Theoretical and Methodological Perspectives on Pedagogical Communication}

Our scientific searches on the topics of pedagogical communication have found that the research on the topic is scarce, as has been the case in the survey of the academic communication studies. William Haskins elaborated on the role of the ethos in the pedagogical communication (Haskins, 2000). Edwards, Nicoll, Solomon, and Usher (2004) spoke of the educational discourses and communication. Another term related to the pedagogical communication is that of Myers-instructional communication. The author has described it as a communication with a focus on the students. The instructing party is the teacher, whereas the instructed one is the student. The objects of study are the verbal and non-verbal communication between the two parties involved in the classroom interaction (Myers, 2010, pp. 149-159). However, there are more references towards the term pedagogical rhetoric, since the training of the contemporary teachers as orators is a vital part of the preparation for their professional practice - they should be able to moderate the pedagogical act, situation and influence their classes as members of the audience. The term pedagogical rhetoric is described by Desyaevoy as a contemporary, codified scientific field, a sub-field of rhetoric. He proposed that the pedagogical rhetoric is a scientific field that creates correlations and conditions for effective professional public speech of the educator. Under the term professional, he classified speeches that are used in the professional communication of the teachers (Desyaevoy, 2013). Lyudmila Gorobets defined the pedagogical rhetoric as a science studying the conditions and the forms of effective pedagogical communication (Gorobets, 2007). Ginka Dimitrova (1996), Sylvia Tsvetanska (2006), and Yanka Totseva (2009) spoke of pedagogical communication.

There are three main elements of the pedagogical communication that could be isolated as important from the definition of Dimitrova (1996): (1) the pedagogical communication as a complex, dynamic, and creative process; (2) it is highly regulated and institutionalized as a practice; and (3) there is a definitive importance of the pedagogical communication in the formation of the student's personality and readiness for the future.

Sylvia Tsvetanska suggested the concept that the pedagogical communication is the main factor allowing the effective conduction of the educational process and that the communicative competences are part of the professional mastery of the teacher (Tsvetanska, 2006). The communicative competences of the teacher are defined as vitally important for the professional readiness in the educational career. 
There are many scholars that define the pedagogical communication in virtual environment. Some of the definitions described are e-learning (Horton, 2006), online learning (O’Neil, Fisher, \& Newbold, 2009), and even online pedagogy (Pelz, 2014). Todor Simeonov gave the definition that describes the pedagogical rhetoric in virtual environment or virtual pedagogical rhetoric - professional type of rhetoric practice in the educational discourse that consists of preparing, sharing, and moderating authentic educational content, combining different modalities, such as text, graphics, audio, video, etc., that are presented synchronously or asynchronously, via the means of ICT (Information Communication Technology) and Internet, while taking into account the needs of the contemporary students in the virtual environment (Simeonov, 2017). As a conclusion, the terms pedagogical communication, pedagogical rhetoric, and virtual pedagogical rhetoric are found in articles and books in Russian, English, and Bulgarian languages. In the scientific literature, we have explored terms, such as educational communication (Edwards, Nicoll, Solomon, \& Usher, 2004), instructional communication (Myers, 2010), as well as pedagogical communication (Dimitrova, 1996; Haskins, 2000; Tsvetanska, 2006; Totseva, 2009), and articles on the realization of the pedagogical rhetoric in virtual environment and its introduction as a virtual pedagogical rhetoric (Simeonov, 2017). We can summarize that the pedagogical communication has a tradition and principles that guide the effective realization of the educational process. Another important conclusion is that there is a clear focus on the audience of students - their needs, individual characteristics, and styles of learning should always be taken into account and catered for through the utilization of the ICT and Internet, as well as the combination of different media channels.

\section{Genres of Academic Communication in Virtual Environments}

The role of the genres in the academic communication (written, oral, and virtual communication) is investigated below. The traditional and well-known academic genres include article, paper, academic essay, review of a book and the book itself, text book, hand-book, monography, dictionary, guide, encyclopedia, collection, repertory, etc. They all have definite place in academic communication. As we can see above, there are a great variety of genres and it is not possible to investigate all genres. In this part of the article, the focus is on two genres: the abstract and the authors' presentation in the context of modern academic communication, as well as they are described in a virtual environment from a methodological and practical point of view.

A special academic genre that enlarges the functions and opportunities of constituting authority is the abstract. The necessity to disseminate the results of scientific investigations and projects quickly is one of the factors for its growing importance. The second one is the intent to inform the different academic communities as specific target groups about the new accomplishments within a particular scientific field. All these actions make more popular the authors of the scientific articles through the abstracts and indirectly they influence the opportunities to establish the authority. The citations and quotations enlarge the possibility for every single author, authors, or research team to become argument from authority and to support his or her academic career.

Contemporary practice shows that abstracts are sent and published online on the sites of scientific conferences. Sometimes the submitting of the application form requires additional information about the author: work, degree, official job position or academic affiliation, publications on the subject of the article, scientific reports, selecting section, etc. The verbal answers to such criteria require clear and credible information prepared preliminary by the participant of the conference. All these elements support the claim that the "apprentice" covers the requirements of authoritative members of the scientific committee. He or she aims to persuade the members of this committee that his or her participation in the conference will be successful. 
Self-evaluation of relevant academic achievements is presented in front of the representatives of scientific communities who make decision for the acceptance or rejection of the offered paper or report.

Writing abstracts has informative and persuasive functions for they support the work of the scientific and organizing committees during the process of working on the conference program. The abstract aims to persuade the members of the scientific committee or the reviewers who are experts and authorities that the text is relevant to the conference and suits to its sections and panels and that the authors will present a contribution to the scientific field. Consequently, it is a specific manifestation of the argument from authority and young researchers improve the manner to write the abstracts in accordance with the academic requirements and submissions.

Depending on the decisions of organizational and scientific committees, abstracts can be published on the websites of conferences or/and issued in small printed collections. The publication of the abstracts in virtual environment allows quick orientation of other participants and readers from academic communities, as well as of editorial boards.

In recent years, abstracts of articles or papers have been published in e-libraries. After a certain period of time (six months, or a year, or a few years), the abstracts are published on the websites of journals themselves and readers can navigate the contents of the article itself, and next, by subscription and/or payment, can receive the article. The visitor is able to send e-mail to the author or editors who are appreciated and accepted as authority. The visitor can ask them to share the text of article or get a free article. This already goes beyond the academic writing and within the scope of academic communication, which is outside the small academic community. The abstract of scientific paper has its dimensions into virtual communities where acts the principle of sharing scientific achievements and results within stipulated norms and rules respected by the members of these communities and the visitors to their networks. The abstracts can have persuasive effect and some of them play a role of the argument from authority.

Relatively new and at the same time approved genres, the abstract or summary, and short self-presentation or bio are frequently used in official presentation and lectures particularly by key speakers, members of scientific committees, editorial board members, etc.

In some cases, the books or collections include the abstracts and information about the authors. The combination of the two genres, abstract of paper/lecture and bio/short presentation of the key speaker, increases their persuasive effect as a specific functioning of the argument of authority.

Simultaneously, official information about an author/authors as well as other genres, such as bio, presentation, self-presentation, which are relatively new communicative genres, is used more often nowadays by the members of academic communities, university management, editorial board, scientific committee, etc. As we have previously stated, the verbal presentations of an author/authors in the books, scientific conference proceedings, call for paper, university sites, academic blogs, sites of research projects, etc., called also "bio", "blurb" or "self-presentation" have a place in academic communication. They are relatively new genres which are often used. They are not typical genres of academic writing, but from communicative standpoint, they include basic information. From our point of view, it is important to say that the credibility of information is an obligatory element of all forms of the genre self-presentation.

To summarize, we can say that the publications about the scientists have both printed and online versions and from methodological standpoint, these electronic sources help to initiate and start research teams or 
communities and scientific networks as well as they guarantee the transparency and establish opportunities to share the information about the researchers from different countries and universities.

\section{Genres of Pedagogical Communication in Virtual Environments}

When it speaks about genre in the classroom, certainly there are some overlappings with the written academic communication genres-essay, book, textbook, hand-book, monography, dictionary, guide, encyclopedia, etc. There are also verbal pedagogical acts, such as the frontal lecture, discussion, brain storming, mind/conceptual map, etc. We could also state that the presentation as a genre already has a stable tradition in the schools all over the world.

There are some new manifestations of the genres with respect to the virtual pedagogical rhetoric communication, such as blog post; and brief online publications - posts, comments, or replies (in websites, social media, and social networks); virtual discussions in small groups, chat; video presentation, multimedia presentation, or screencast presentation. Other genres that could not be classified as rhetorical, but are part of the pedagogical communication in virtual environment are the e-mail, poll or questionnaire, online assignments; tests, and quizzes. As with/Similarly to the academic communication genres, we will concentrate on two relatively new manifestations of the pedagogical communication genres in virtual environment: the videocast or video presentation lesson and the screencast presentation.

The multimedia, screencast, and videocast or video presentations are based on the principles of multimodality. The term "multimodality" is introduced by Gunter Kress in his book "Multimodal Teaching and Learning: The Rhetorics of the Science Classroom" (Kress, 2001).

There is an example in Bulgaria of a website-Ucha.se, which creates multimodal video presentations that cover the whole course of studies in the Bulgarian state school from 1st to 12th grade. This is an innovative website for students and teachers. The video lessons are designed and shared on the website and cover core standards in almost all school subjects: Mathematics, Bulgarian language, Literature, Chemistry, Physics, as well as foreign languages, such as English, German, Russian, Spanish, and French, in accordance with the European Language Framework.

The visuals presented in the videos (graphics, pictures, drawings, etc.) address the visual style of learning as well as multimodality in different subjects: languages, humanitarian topics (historical processes, writers, books), and sciences (Mathematics, Chemistry, Physics). In addition, the students receive the knowledge in the virtual environment and the dynamic and interactive pedagogical communication helps them to be active members of virtual community.

The screencasts as a form of pedagogical presentation contain video, audio, graphic, and interactive elements that address the needs of every type of learner: the visual, the audial, and the kinesthetic (Simeonov, 2016). The organization of the educational content in the form of screencast is an easy way to combine multimodal elements, without the need to have extensive visual and computer graphic design competences and skills. Most screencast software programs allow for the combination of the following elements: text, photos, pictures, graphics, video, audio, direct noting and drawing at the screen, use of interactive elements (with Microsoft Mix) that add a didactical function to the screencast (checking attention and understanding with short questions/quizzes). Many of the Coursera video lessons are organized as screencasts and then exported in a video format. The practice shows that there are plenty of virtual classrooms like Edmodo, Google Classroom, Moodle, Blackboard, Class Dojo, etc., that could help the teacher share the content with the students. The 
screencast technology facilitates the pedagogical communication in such a way that not only the teacher, but also the students can learn to create screencasts in the educational process as they complete different tasks and projects. That specific genre not only provides the possibility for passive reception of the educational content, but also allows for the active construction of knowledge and the building of digital competences of the students.

We can conclude that the genres that are present in both the academic and the pedagogical communication derive from the traditional educational genres, such as essays, books, abstracts, discussions, frontal lectures, etc. But also, there are new manifestations in virtual environments (e-mail, blog posts, social network and media posts, chat discussions, multimedia, screencast, videocast presentations) and they are realized via Internet and, in particular, via the platforms, e-resources, software programs, and channels, such as Edmodo, Google Classroom, Moodle, Blackboard, etc., which facilitate the realization of the contemporary education in the universities and schools.

\section{Traditional and New Communication Channels and Practices in the Educational Discourse}

Traditionally, we find and read scientific information in official sources evaluated as authoritative, for example, scientific articles, papers, and academic essays published in prestigious journals and magazines. In the 21 st century, there is a wide interest in using Internet and web-based communication applications for educational purposes (Veerman \& Veldhuis-Diermanse, 2001) and channels. Online dictionaries and encyclopedias are accepted as authoritative sources if they are developed by distinguished scientific teams, members of academic institutions, societies, associations, etc. The reputation of the institutions or experts is the base to appreciate them as contributors, inventors, or discoverers of importance. One of the main criteria to evaluate somebody as the authority in a certain scientific field is the credibility of the sources used by them. Simultaneously, easy access to the articles and papers as scientific sources increases their popularity and indirectly influences the building of the authority.

Only two decades ago, the opportunities to find basic and up-to-date scientific information broadened dramatically as a result of the technological development, new generations of Internet esp. Web 2.0, digital competence of researchers, growing need for information about scientific contributions and achievements, etc. Some lecturers and researchers started publishing in personal or collaborative academic blogs designed to support university education and particular teaching on one or similar topics, subjects, and curriculums.

We have tried to define the term "academic blog" starting from good practices. Academic blogs are managed by representatives of various academic communities (university lecturers, teachers, students, members of scientific associations or research project teams, librarians, etc.). They provide information following the principles of creating and maintaining blog posts for the purpose of university education within a particular course on the faculty, BA, and MA programs, as a part of the projects and conferences. Academic bloggers start from the wish to share knowledge and provide sources of scientific information following the principle of being useful for academic subjects.

Online collaboration has immensely enlarged during the recent years. Academic websites and blogs have become inseparable parts of academic communication and gradually have been accepted as regular sources of scientific information. Their credibility has no longer been seen as excessively disputable and has increased within certain limitations and in concern with its academic space, target audience, and goals. The dominating position is that academic classes present solid knowledge provided by trained professionals, experts, and teachers who are highly educated and have positions in educational institutions; that are authorized to 
participate in the process of teaching and learning at universities and the management of scientific journals and publications, as well as to act as academic publishers. This understanding is valid now and there are sufficient grounds for that. Simultaneously, university teachers and educational management of some universities have already shifted to other channel resources and training opportunities, taking into account the benefits of new technologies-Web 2.0 sites, forums, social networks, and social media.

The online platforms for education, such as MOOCs, offer advantages not only for learning in a convenient place and time, but also the flexibility of information exchange and the option for virtual communication. The information can be easily presented, stored, and accessed in multiple formats (text, graphics, quizzes, video lectures, etc.). The communication between students and teachers can be facilitated by blogs and forums. The models of virtual academic communication have the possibility to discuss complex problems from different perspectives. Students exchange information or discuss the most important parts from the courses. They can also exchange their roles of students and become peer-reviewers of other students. The collaboration has become an inseparable part of virtual academic communication and it provokes activity and stimulates the students to be more active during the educational process.

Teachers use the Web 2.0 technologies in schools as well. They could not allow themselves to lag behind with the ever-increasing rate of new technologies that "pop-up" in the hands of their students every day. Blogs are used to establish various collaborative tasks, but school educators also use different virtual tools to create virtual environment. This virtual spaces and networks support and enrich the pedagogical goals (Light \&Polin, 2010); they widen the capacities of schools for education, as they transfer some of the knowledge outside the school "walls". Researchers, such as Lourdes Guardia, Marcello Maina, and Albert Sangra (2013), discussed the need for new pedagogical tools in the learning process. The new generations of students require a new model of teaching and learning. These new tools introduce a specific importance of the technologies used in schools, such as Facebook, Twitter, Wikkies, Pintres, Google Classroom, LinkedIn, Edmodo, Blackboard, etc., that their unique functionalities create conditions for social learning between students, between students and teachers, and between teachers (Simeonov, 2015). That is a prerequisite for a learning of a new type - conducted with the possibilities granted by the information and computer technologies and Internet.

In conclusion, we can stipulate that the new information and computer technologies and Internet as channels allow lecturers, researchers, and teachers to use modern ways to present their contributions, to promote themselves as authorities, and to facilitate the learning process for their students. Therefore, they are acting to support university and school education and training and are part of a virtual educational communication.

\section{Conclusion}

We can summarize that academic communication and pedagogical communication have specific spheres of manifestation. At the same time, they are influenced by the dynamic development of the Internet-Web 2.0, Web 3.0, even Web 4.0. It is obligatory that universities' lecturers and students, teachers and pupils follow the model including the continuous improvement of digital and multimodal competence and interactive communication skills for the virtual communities. At the same time, it is very important to develop the competences on the levels of genres (abstracts, presentations, papers, essays, blog posts, video lectures, etc.) for the students and professors; and posts, quizzes, screencasts, presentations, etc., for the teachers and pupils). Third, professors and students, universities' management and administration, teachers and pupils, school organizers and parents have found a balance between online and offline communication. 


\section{References}

Carrascal, B., \& Hundleby, E. (2011). Authority arguments in academic contexts insocial studies and humanities. Retrieved from http://scholar.uwindsor.ca/cgi/viewcontent.cgi?article=1019\&context=ossaarchive

Desyaevoy, H. D. (2013). Pedagogical rhetoric. Moscow: Publishing Center “Academy”.

Dimitrova, G. (1996). Pedagogical communication in the educational process. Sofia: "Veda Slovena-JG".

Edwards, R., Nicoll, K., Solomon, N., \& Usher, R. (2004). Rhetoric and educational discourse: Persuasive texts. London: Routledge Falmer.

Gorobets, L. (2007). Pedagogical rhetoric in the system of professional training of the teacher-non-philologist (pp. 132-145). Notifications of the Russian State Pedagogical University, A. I. Gerzena.

Guàrdia, L., Maina, M., \& Sangrà, A. (2013). MOOC design principles. A pedagogical approach from the learner's perspective. E-Learning Papers, 33. Retrieved from http://r-libre.teluq.ca

Haskins, W. (2000). Ethos and pedagogical communication: Suggestions for enhancing credibility in the classroom. Current Issues in Education, 3, 2.

Horton, W. (2006). E-learning by design. San Francisco: Pfeiffer.

Hyland, K. (1997). Persuasion and context: The pragmatics of academic metadiscourse. Journal of Pragmatics, 30(4), 437-455.

Hyland, K. (2002a). Authority and invisibility: Authorial identity in academic writing. Journal of Pragmatics, 34, 1091-1112.

Hyland, K. (2002b). Options of identity in academic writing (pp. 351-358). Oxford: Oxford University Press.

Hyland, K. (2003). Self-citation and self-reference: Credibility and promotion in academic publication. Journal of the American Society for Information Science and Technology, 54(3), 251.

Kress, G. (2001). Multimodal teaching and learning: The rhetorics of the science classroom. London: Continuum.

Light, D., \& Polin, D. (2010). Integrating Web 2.0 tools into the classroom: Changing the culture of learning. New York: EDC Center for Children and Technology.

Mavrodieva, I., \& Tisheva, Y. (2010). Academic communication. Sofia: Sema RSh.

Mavrodieva, I. (2011). Virtual academic communication: Theoretical and practical manifestations in e-learning and distance education. In Electronic, distance education in 21 century, E-journal for electronic education, Sofia University. Retrieved from http://journal.e-center.uni-sofia.bg/f/downloads/2011/Broi\%202/I.Mavrodieva.pdf

Mavrodieva, I. (2012). Rhetorical features of academic presentations. Rhetoric and Communications E-Journal, 4. Retrieved from http://rhetoric.bg/

Mavrodieva, I., \& Tisheva, Y. (2014). Academic writing for PhD students and postdoc. Sofia: Sofia University Press.

Mavrodieva, I., \& Tisheva, Y. (2016). From the retreat to master thesis. Academic writing for students. Sofia: Uchebnik BG.

Myers, S. (2010). Instructional communication. The Emergence of a field. In D. Fassett and J. Warren (Eds.), The SAGE handbook of communication and instruction (pp. 149-159). USA: SAGE Publications.

O’Neil, C., Fisher, C., \& Newbold, S. (2009). Developing online learning environments: Best practices for nurse educators. New York: Springer Publishing Company.

Pelz, B. (2014). My three principles of effective online pedagogy. Journal of Asynchronous Learning Networks, 8(3), 33-46.

Simeonov, T. (2015). Application of business software solutions in education. In T. Shopova and A. Nikolova (Eds.), Information technologies, culture and society (pp. 306-317). Blagoevgrad: University Press "Neofit Rilski".

Simeonov, T. (2016). Screencasting: Transformation of the pedagogical presentation viewed through cyberethnography. Rhetoric and Communications E-Journal, 20. Retrieved from http://rhetoric.bg/

Simeonov, T. (2017). Virtual pedagogical rhetoric: A new way of fostering 21 st century competences for teachers and students. Paper presented at The 4th ESTIDIA Conference, Dialogues Without Borders: Strategies of Interpersonal and Inter-group Communication. Sofia: Sofia University Press; Institute of Rhetoric and Communication, Sofia.

Totseva, Y. (2009). Pedagogical rhetoric and pedagogical communication. Rhetoric and Communication E-Journal, 12. Retrieved from http://rhetoric.bg/

Tsvetanska, S. (2006). Challenges in pedagogical communication. Sofia: Prosveta.

Veerman, A., \& Veldhuis-Diermanse, E. (2001). Collaborative learning through computer-mediated communication in academic education. In Collaborative learning, reasoning, and technology (pp. 323-355). Maastricht: Maastricht University Publishing. 